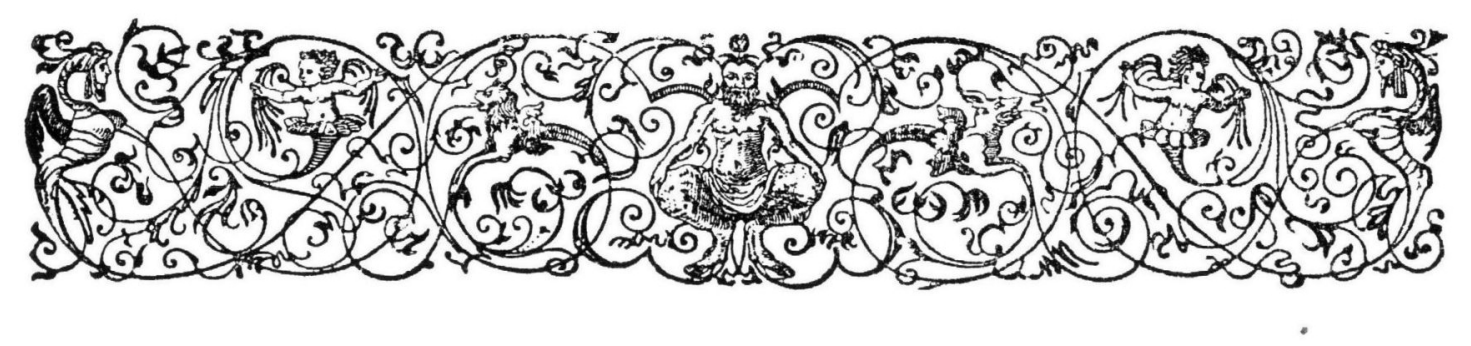

\title{
EEN WESTFRIESCHE ROLAND
}

DOOR

\author{
DR. J. HUIZINGA.
}

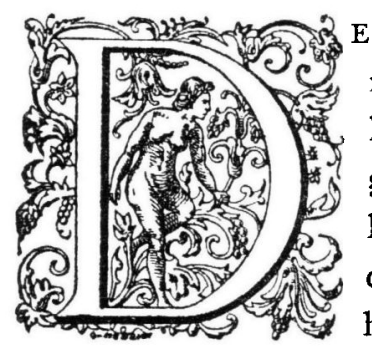

vraag naar den oorsprong en de beteekenis der zoogenaamde Rolandsbeelden is door Mr. S. Gratama in een bespreking van een Duitsch werkje over dit onderwerp met reden genoemd "een vraagstuk, dat uit den aard der zaak hier te lande minder belangstelling heeft gewekt dan aan de overzijde der grens. In geen onzer steden toch wordt een beeld van hout of steen gevonden, dat met den naam "Roland" wordt bestempeld." 1) - Het moet inderdaad het plechtige staren van de raadselachtige oude figuren zelf zijn geweest, dat in Duitschland reeds meer dan drie eeuwen lang zulk een stroom van verhandelingen en beschouwingen: historisch, juridisch, archeologisch, in de eerste plaats fantastisch, heeft uitgelokt. Onder hen, die er hun vernuft aan hebben geschonken, treffen wij MELANCHTHON en LEIBNIZ, om van minderen te zwijgen.

Het gebied van verspreiding der echte Rolanden laat zich aldus omschrijven: een gesloten gebied in Oostfalen tusschen Harz en Midden-Elbe, met een uitlooper Nordhausen in Thuringen en een uitham aan de overzijde der Elbe tot in de

1) Museum, rze jaargang, bl. 440: Heldmann, Die Rolandsbilder Deutschlands in dreihundertjähriger Forschung und nach den Quellen.

Oud-Holland 1907 . 
Neumark Brandenburg, voorts eenige verstrooide Rolanden in het Westen (Hamburg, Bremen) en in het Oosten (Elbing, Riga). ${ }^{1}$ ) - Van de echte Rolanden. Buiten het omschreven gebied van Saksisch recht waren een menigte plaatsen, die op het bezit van zulk een eerwaardig monument, ' $t$ zij nog bestaand of slechts in de historie vermeld, prat gingen. Al die aanspraken zijn door den verdienstelijken „Rolandsforscher" GEORG SELlo krachteloos gemaakt, tal van pseudo-Rolanden uit het onderzoek geroyeerd; en daarmee is de basis daarvan verbeterd. Zijn vonnis luidt: „dass alle Rolande, welche westlich und südlich einer im Wesentlichen clurch Weser, Thüringerwald, Erzgebirge, Riesengebirge markirten Grenzlinie genannt werden, jeder historischen Legitimation baar ihre fragwürdige Existenz antiquarischer Wichtigthuerei verdanken," 2) en strengelijk worden de ontmaskerden uitgewezen: "In der Rolandgeschichte ist kein Platz für dieselben." 3).

Onder die gebannenen telt SELlo ook éen gewaanden Roland op Nederlandsch gebied, namelijk te Amsterdam. Hij verwerpt dien mijns inziens volkomen terecht, zooals ik hier beneden uitvoeriger zal toelichten. Maar nu moet ik voor een anderen Nederlandschen Roland, waarop, voor zoover mij bekend is, de aandacht nog niet is gevallen, een heel bescheiden plaatsje in het onderzoek bepleiten.

Voor den Nederlandschen lezer evenwel mag daaraan een vluchtig overzicht van den stand der kwestie wel voorafgaan. Een overzicht, dat op eigen kritiek over de opgesomde verklaringshypothesen geen aanspraak maakt, en zich tot het hoog noodige bepaalt, onder verwijzing naar de reeds aangehaalde geschriften van Sello en Heldmann en de nog te vermelden opstellen van R. Schröder, S. Rietschei, en anderen.

Daar hebben wij dan allereerst de onvermijdelijke mythologische verklaring. De hemel beware mij er voor, met geringschatting te spreken van een verklaring, waarover JAKOB GRIMM het licht van zijn genie heeft laten schijnen. Maar het is iets anders, of wij met de aandoening, die GrImM's gedachten altijd wekken, ook wanneer zij ons het minst gegrond schijnen, van een meer vermoed dan betoogd verband tusschen „Irmensäulen und Rolandsäulen” lezen ${ }^{4}$ ), dan of wij

1) Rifatschet, Historische Zeitschrift 89, S. 485; G. SELt,o, Der Roland zu Bremen, Bremen Igot, S. 3 ; id., Zur Litteratur der Roland.Bildsäulen, Deutsche Geschichtsblätter, 2, S. 2. - De ouderdom der nog bestaninde beelden gaat zekcr niet de $1_{4}$ e eeuw te boven.

2) Der Roland zu Bremen, S. z.

3) Roland-Rundschav, Deutsche Geschichtsbläiter, 4, S. I7o.

4) Irmenstrasse und Irmensäule, I8I5; Deutsche Mythologie2, 366 ; vgl. SELlo, D. Geschichtsbl. 2, S. 74; Heldomans, a. a. O., S. 48. - Later stelt Grimm de Rolandsbeelden niet ouder dar de I4e eeuw. Over een verklaring van Elard Hugo Meyer zie Sello en Heldmann, aldaar. 
vernuftige mythologische combinaties van den allerjongsten tijd lezen, waarvan Paul Platen de uitvinder is ${ }^{1}$ ). De verklaring weifelt tusschen Donar en Tiu, dat zij hier genoeg.

Een tweede hypothese heeft door den beroemden naam van RICHARD SCHRöDER gezag en verspreiding gekregen. Geheel nieuw was zij niet, trouwens reeds sedert de 17 de eeuw beweegt zich het onderzock feitelijk tusschen drie of vier mogelijkheden van verklaring. Door den samenhang met SoHM's geruchtmakende theorie van het ontstaan van het stadrecht kreeg SCHRöDER's verklaring, die hij zelf later aanmerkelijk gewijzigd heeft, nog een bijzondere aantrekkelijkheid. In haar laatste formuleering komt zij hierop neer. ") Als teeken van den marktvrede diende reeds in den Frankischen tijd bij voorkeur het marktkruis. Uit de eigenaardige neiging tot opcenhooping van symbolen, die hetzelfde beduidden, sproot het voort, wanneer aan dat kruis nog andere teekens van den koningsban werden gehecht: handschoen, zwaard, vaan, hoed enz. In de vaste marktplaatsen werden die marktteekens in blijvenden, dikwijls monumentalen rorm aangebracht: het marktkruis werd stadkruis. Sinds het einde der I 3 e ceuw trad in vele Noordduitsche steden in de plaats van het kruis een Rolandsbeeld, dat dus heeten mag: de monumentale drager der gebruikelijke marktteekens.

Deze verklaring trachtte SCHRöDER als de noodzakelijke te bewijzen, door de andere hypothesen, die voor en na geopperd waren, te elimineeren. Teekens van de hooge jurisdictie kunnen het niet zijn, redeneert hij, want zij komen voor op plaatsen, die nimmer de hooge jurisdictie bezeten hebben. Teekens van rijksvrijheid evenmin, want van al de steden, waar Rolandsbeelden voorkomen, gold alleen Nordhausen reeds in de Middeleeuwen als rijksstad. Teekens van stadrecht zijn het ook al nict, want zeven Rolanden hebben gestaan in marktvlekken of dorpen, die ecrtijds markten zijn geweest. Derhalve kunnen het slechts marktsymbolen zijn geweest.

Alleen op deze negatieve argumentatie berustte eigenlijk ScHRöDER's bewijs. Positief kon hij de betrekking tusschen den Roland, respective het vaste kruis, en de markt niet aantoonen, gelijk reeds KEUTGEN betoogde. ${ }^{3}$ ). Bij geen enkelen Roland vindt men inderdaad de marktteekens kruis of vaan aangebracht;

1) P. Platen, Zur Frage nach dem Ursprung der Rolandssäulen, 1899 ; Der Ursprung der Rolande, IGOI; id. Ig03; zie HetduMANn, S. 5 I ff.

2) R. SchröDER, Weichbild, in: Histor. Aufsätze zum Andenken an G. WAitz, I886, S. zo6; Die Stellung der Rolandssïulen in der Rechtsgeschichte, in: Die Rolande Deutschlands, Festschrift, x890, S. I; Marktkrcuz und Rolandsbild, in: Festschrift für K. WeInhold, I8g6, S, II8; Lehrbuch der Deutschen Rechtsgeschichte I902, S. 625. - Vgl. SoHM, Die Entstehung des deutschen Städtewesens, S. 28.

3) Untersuchungen über den Ursprung der deutschen Stadtverfassung, 2895, S. 72. 
SCHRöDER beriep zich te dien opzichte op onechte Rolanden. ${ }^{1}$ ). Niet van al de dorpen, die een Roland bezaten, was het bewijs, dat zij eenmaal marktplaats waren geweest, geleverd.

De veronderstelling, dat de Roland als drager dient van een symbool van den koningsban, 't zij dan met bijzondere betrekking tot den marktvrede of niet, strekt ook tot uitgangspunt voor de verklaring, waardoor RIETSCHEL in zijn Markt und Stadt die van SCHRöDER heeft getracht te verdringen, en waarvoor hij den bijval van velen, o. a. vON BELOw ${ }^{2}$ ), heeft gevonden.

$\mathrm{Na}$ te hebben betoogd, dat er geen positieve bewijzen zijn voor het verband van den Roland met de markt, wijst RIETSCHEL er op ${ }^{3}$ ), dat op verschillende plaatsen executies en rechtzittingen vóor den Roland worden gehouden, een gewoonte, die reeds voor de $\mathrm{I}_{4} \mathrm{e}$ eeuw te bewijzen is. Het hooggerecht van den schout van Halle heeft plaats voor den Roland, de schepenvonnissen worden er 'auf dem Schöffenstuhle vor dem Roland' geveld. Die van Elbing draagt 'halsyser', dient derhalve als kaak ${ }^{4}$ ), gelijk op meer andere plaatsen.

Wijzen reeds deze omstandigheden er op, dat men den Roland opvatte als „Wahrzeichen der Blutgerichtsbarkeit", RIETSCHEL heeft voor die verklaring nog gewichtiger argumenten. Het hoofdattribuut van den Roland, dat behalve bij een paar zeer late beelden, aan allen gemeen is, is het breede, rechte, bloote zwaard, dat hij in de rechterhand draagt met de punt naar boven. Een scheede aan den gordel draagt geen der oudere beelden. Welnu, gaat RIETSCHEL voort ${ }^{5}$ ): „Das Schwert ist also nicht die Kriegswaffe des geharnischten Mannes, es wird von ihm nicht an der Seite getragen; er hat es nur zum augenblicklichen Gebrauche in die Hand genommen, um es dann wieder wegzulegen. Ein solches nur zeitweise in Benutzung genommenes Schwert ist aber des Richtschwert. Offenbar haben wir also in dem Schwerte des Rolandes das Gerichtsschwert, das Symbol der hohen Gerichtsbarkeit, zu erblicken. Der Roland aber verkörpert den Träger dieser Gerichtsbarkeit, mag man nun - wofür sich SELlo entscheidet - an den höchsten Richter, den König oder Markgrafen, oder an den niederen Inhaber des Gerichtsbannes, den mit gräflichen Rechten ausgestatteten Landesherrn oder (bei geistlichen Fürsten) seinen Vertreter im Hochgerichte, den Vogt, denken."

Voor deze in 1897 opgestelde verklaring heeft RIETSCHEL later nog andere

1) Rietschel, Markt und Stadt in ihrem rechtlichen Verhältnis, 1897, S. 230; Sello, D. Geschichtsbl. 2, S. 70 .

2) Städtewesen und Bürgerthum, S, 63 .

3) Markt und Stadt in ihrem rechtlichen Verhältnis, S. 227 ff. - Ook deze verklaring sluit reeds bij oudere onderzoekingen aan.

4) Rietscher, Historische Vierteljahrschrift, 9 (1906) S. 539; Markt und Stadt, S. $229^{7}$.

b) Markt und Stadt, S. 23I. 
aardige argumenten bijgebracht ${ }^{1}$ ). Naast het zwaard is het in 't oog vallendste kenteeken der oudere Rolanden, dat zij blootshoofds staan. Schrijft nu niet de Saksenspiegel $3,69, \$$ I voor, dat rechters, die bij koningsban dingen, noch kappen noch hoeden, noch hoedjes noch huiven zullen dragen? Ook de mantel, die hun daar voorgeschreven wordt, wordt door sommige Rolanden gedragen. Het is geheel en al de rechter uit de verluchte handschriften van den Saksenspiegel. Het oudste Rolandtype, onbetwijfelbaar die te Halle, die een $13^{\mathrm{e}}$ eeuwsch model vertoonts), leidt dus èn door zijn uiterlijke kenteekenen èn door zijn vroegere bestemming tot de verklaring, die RIETSCHEL met steeds grooter stelligheid heeft herhaald: „Das monumentale Bild sollte zweifellos nicht anderes bedeuten als die dauernde Gerichtsherrschaft des fürstlichen Stadtherrn über die Stadt." 3) Waar hij voorkomt in steden, die nooit de hooge jurisdictie hebben bezeten, moet men den stadheer als den oprichter van het beeld beschouwen, misschien juist ter herinnering aan zijn gezag. Waar de Roland harnas, handschoenen en schild draagt, die op zichzelf bij den rechter niet passen, moet men een jongere wijziging van het type aannemen.

Beslist ontzenuwende argumenten schijnen or tegen RIETSCHEL's verklaring niet aan te voeren te zijn. SELLo maakt er zich heel gemakkelijk af, door het samengaan van beeld en rechtshandeling zuiver toevallig te noemen. 4) HELDMANN erkent, dat de Roland van Halle, de gewichtigste steun voor RIETSCHEL's hypothese, een standbeeld van den gewonen rechter, een symbool der hooge jurisdictie is, maar tracht vervolgens dien Hallenser Roland zelf als niet-typisch, niet-authentisch te disqualificeeren, ${ }^{5}$ ) het is geen echte Roland, beweert hij. Ook SCHRöDER geeft toe, dat de Roland van Halle als de met den koningsban bekleede rechter moet worden opgevat, doch betwijfelt, of daarom altijd bij elken Roland aan een kenteeken der hooge jurisdictie is gedacht: het zwaard kon evengoed op den koningsban in het algemeen doelen, terwijl het dan in Halle speciaal op den gerechtsban, in Münster ${ }^{8}$ ) op den marktban sloeg. ${ }^{7}$ )

Eén methodisch gebrek kleeft RIETSCHEL's verklaring aan, waarop KEUTGEN gewezen heeft ${ }^{8}$ ), nl. dat hij afzien moet van de eenige oude traditie omtrent de

1) Historische Zeitschrift 89 ( $\left(\mathrm{gO}^{\circ}\right)$, S. 457 , Ein neuer Beitrag zur Rolandsforschung (G. SELLO, Der Roland zu Bremen); vgl. Hist. Vierteljahrschrift, 8, S. 86; 9, S. 535 .

2) Hoewel het hujdige beeld eerst uit I7I 8 stamt.

3) Hist. Zeitschr. 89, S. 464 .

4) D. Geschichtsbl. 2, S. 73 .

5) Die Rolandsbilder Deutschlands, S. $62-76$; opnieuw in : Rolandsspielfiguren, Richterbilder oder Königsbilder, 1905, zie RIETsChel, Hist. Vierteljahrschr. 9, S. 539.

6) Waar een arm met een zwaard ten tijde der markt uit den toren werd gestoken.

7) Zeitschrift der Savigny-Stiftung, 27 (Ig06), S. $4^{62 .}$

8) Deutsche Lit. Ztg. Ig03, Sp. 9r-94. 
beteekenis van den Roland, die ons uit de Middeleeuwen zelf is bewaard, die van den Roland van Bremen.

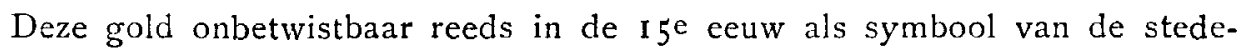
lijke vrijheid. Hieraan knoopt Sello zijn hypothese ${ }^{1}$ ). Hoe is het Bremer beeld ${ }^{2}$ ) aan die beteekenis gekomen? Men kan het niet beter verklaren dan door aan te nemen, dat het oorspronkelijk een standbeeld van den stadstichter OTTO I is geweest, een "Leibzeichen" van den koning, door den aartsbisschop ADALDAG (936-988) opgericht ten teeken, dat Отто I hem met den gerechtsban over de nieuwe stad had beschonken. Zoo te Bremen, zoo ook te Maagdenburg. Naarmate de steden zelf hun vrijheid op den stadheer veroverden, werden de beelden als teekenen der stedelijke vrijheden aangezien, vonden als zoodanig navolging in vele Saksische steden, in het bijzonder die met Maagdenburger recht, en werden, terwijl men OTTO I snood vergat, weldra voor KAREL DE GROOTE later voor diens paladijn Roland aangezien. Tot de laatste naamswijziging zou hebben bijgedragen, dat de Duitschers op de tochten naar Italië in de $\mathrm{I} 2^{\mathrm{e}}$ ecuw in de kerken van Lombardije, o.a. te Verona, beelden hadden leeren kennen, die Roland voorstelden, en zeer veel op de Noordduitsche koningsbeelden geleken.

SELLo's verklaring rust niet op bijzonder soliede gronden. Haar kracht ligt in het punt van uitgang: de Bremer Roland geldt reeds in de Middelceuwen als symbool der stedelijke vrijlieid. Maar de verdere opbouw is wankel. Daargelaten dat het niet al te best strookt met wat wij weten omtrent de kunstgeschiedenis van Noord-Duitschland, om aan te nemen, dat de aartsbisschoppen van Bremen en Maagdenburcs in de $10^{e}$ eeuw standbeelden zouden hebben opgericht voor OTTO $\mathrm{I}$, is het type der Rolandsbeelden voor de verklaring als koningsbeelden niet gunstig. De kroon, die steeds de middeleeuwsche koningsbeelden kenteekent, ontbreekt bij alle oudere Rolanden, evenals schepter, rijksappel of vaan.

De belangrijke verdiensten van SELLo liggen dan ook naar het algemeene oordeel meer in de zorgvuldige kritische verzameling en schifting van het bronnenmateriaal, in het vaststellen van herkomst, authenticiteit en ouderdom der beelden, dan in zijn eigen hypothese.

Het gewichtigste argument voor het vaststellen van den ouderdomstermijn vond SELlo in een plaats van de Magdeburger Schóppenchronik, die op het jaar 1278 voor het eerst melding maakt van het Rolandsspel, dat later in verschillende streken van Noord-Duitschland voorkomt: het rijden en steken naar

1) Der Roland zu Bremen.

2) In $\mathbf{3 4 0 4}$ op last van den Raad weer opgericht, nadat het oude in 1366 was vernield. 
een houten pop, waarover straks nader. SEILo vermoedde, dat men den naam Roland van het beeld op de markt spottenderwijs op die speelpop had overgedragen, en vond daarin het bewijs, dat de marktbeelden reeds in de $13^{\text {e eeuw }}$ Roland genoemd werden ${ }^{1}$ ).

Door deze verhouding van marktbeeld en speelpop om te draaien, heeft nu Heldmans een geheel nieuwe verklaring van het probleem, tot nu toe de laatste, gevonden, die hij met evenveel eigen zekerheid als kennis en scherpzinnigheid verdedigt.

In de meeste oudere Rolandplaatsen is een houten Roland aan den lateren steenen voorafgegaan. Welnu, zegt HELDmaNN, die oude houten Rolanden waren niets anders dan de houten poppen, die voor het Kolandsspel dienden. Het is het spel, dat in het Middelnederlandsch Quinteine heet ${ }^{2}$ ). In zijn meest ontwikkelden vorm is het aldus: jonge lieden rijden met gevelde lans tegen een draaibare houten figuur, die in de eene hand een schild met een ring of iets dergelijks draagt, in de andere een zak met asch of meel, of een los bevestigden knuppel. Het is er om te doen den ring er uit te steken en tegelijk de aschof meelzak of den knuppel te ontgaan. Dit spel werd door het stadsbestuur zelf in eere gehouden, en verheugde zich in groote belangstelling; de speelpoppen stonden op de markt en werden nu en dan van stadswege vernieuwd of opgeschilderd.

De overgang nu van speelpop tot symbool van stadsvrijheid of hooggerecht is volgens HELDMANN in Bremen te zoeken. De oude houten Roland was in 1366 verbrand. Omstreeks 1400 was Bremen er op uit, met allerlei middelen zich de suprematie in de Hanze te verzekeren, bij voorbeeld door een reeks van oorkondenvervalschingen, waaraan de burgemeester JOHAN HEMELING de voornaamste schuldige moet zijn geweest. Hij zou o. a. in een Bremer stadskroniek verschillende plaatsen hebben geinterpoleerd, waar van den Roland wordt gesproken in verband met een vervalschten vrijheidsbrief van HENDRIK $V$ uit III, en tot staving van Bremen's aanspraken zou het dezelfde HemelixG zijn geweest, die in I4O4 een nieuwen kolossalen Roland, na dezen behendig als symbool der stedelijke vrijheid te hebben geïnterpreteerd, heeft doen oprichten. Andere steden zouden voor en na Bremen's voorbeeld hebben gevolgd en hun houten spel-Rolanden door steenen figuren hebben vervangen, die dan hier als symbool der stadsvrijheid, daar van het hooggerecht werden aangezien.

HELDMANN'S uiteenzetting van de Bremer vervalschingskwestie is uiterst

1) Der Roland zu Bremen, S. I2 ft. - SELlo's pogingen, het roorkomen der beelden reeds in de rze eeuw te bewijzen, worden door Rietschel mislukt geacht, Hist. Zeitschr. 89, S. 459.

2) Zie het artikel Quinteine in het Mnl. Wdb. 
scherpzinnig, en de verklaring, die hij daarmee gegeven heeft van het feit, dat de Roland van Bremen sedert de $\mathrm{I}^{\mathrm{e}} \mathrm{e}$ eeuw als symbool der stedelijke vrijheid geldt, wordt algemeen als zeer gelukkig beoordeeld. Ik ga daarop niet verder in. ${ }^{1}$ ) Het bewijs evenwel, dat de voormalige Rolanden niets anders zijn geweest dan poppen voor het steekspel is daarmee in 't minst niet verder gebracht. Het blijft ontbreken, tenzij men een snuggeren inval mocht toejuichen, die thans ook den naam Roland als 'rollend', van lat. rotulare, weet te verklaren. ${ }^{2}$ ) - HeldmanN's opvatting is door velen hoofdschuddend ontvangen; SELLo, RIETSCHEL, SCHRöDER en KEUTGEN verwerpen haar ${ }^{3}$ ), ook nadat HELDMANN in een nieuw geschrift zijn bestrijders heeft te woord gestaan, terwijl Gratama, BeyerLe en Heck haar niet onaannemelijk achtten. ${ }^{4}$ )

De bedenkingen van SCHRöDER en RIETSCHEL, naar mijn oordeel overtuigend, betreffen beide de psychologische onmogelijkheid, zich de toedracht zóo voor te stellen, als HELdmanN wil. Tot in de $14^{\mathrm{e}}$ eeuw heeft men lustig Roland gespeeld. Het spel raakt uit de mode, de houten poppen verkwijnen, totdat plotseling een Bremer politicus op den inval komt, ze te verheffen tot symbolen van wat de stad het allermeest ter harte ging, haar vrijheid. En al de andere steden vinden die metamorphose zoo kostelijk, dat ze zich haasten, haar na te volgen! - Zoo begrijpelijk het is, wanneer wij een ernstig rechtssymbool geparodieerd zien, zoo ondenkbaar is zulk een overdracht. SCHRöDER vraagt met een geestige vergelijking, of dan iemand er aan denken zou, de houten duif, waarop in zijn Pommersch geboortestadje in zijn jeugd nog werd geschoten, thans, nu ze uitgediend heeft, tot rijksadelaar te verheffen.

Bovendien, de speelpoppen werden slechts tijdelijk opgesteld, volstrekt niet altijd op de markt, en na de feestelijkheid opgeborgen. En het type der Rolandsbeelden klopt er slecht mee: juist het zwaard kan de spel-Roland bezwaarlijk gedragen hebben, en de pop had natuurlijk uitgestrekte armen. En eindelijk: als de spel-figuur primair was, zou dan de naam Roland te begrijpen zijn? Zulk een pop heet Turk of Saraceen (zooals in de Quinteine inderdaad voorkomt), maar niet naar KAREL's roemrijksten held, den bestrijder der ongeloovigen. Om het alweer, nu met RIETsCHEL, over te brengen in onzen tijd:

1) Men zje IIfldmans's Die Rolandsbilder Deuischlands, S. 98-170; verder PH. Heck, Dic Rolandsstelle des Bremer Heinricianums, Hist. Vierteljahrschrift 9, (IgO6), S. I25, 305; Gratama, Museum I2, 440.

2) Jostes, Roland in Schimpf und Ernst, aangehaald door RIETschel, Hist. Vierteljabrschrift, 8, S. $87 ; 9$, S. 537. - HeLdMANn zelf aanvaardt die etymologie niet.

3) Sello, Vindiciae Rulandi Bremensis; RIETSChel, Hist. Vierteljahrschrift, 8, S, 86; 9, S. 535 ; Heldmann, Rolandsspielfiguren, Richterbilder oder Königsbilder, Halle I905; Schröder, Zeitschrift der Savigny-Stiftung 27 , S. 457 ; KeUTGeN, Literaturblatt für germ. und rom. Philologie 1905, S. 355 ,

4) Gratama, Museum 12, 440; Beyerle, Zs. der Savigny-Stiftung 25, S. 393; Heck, Hist. Viertelj. 9. S. 125,305 . 
zoo'n mikpunt heet NAPOLEon maar geen Moltke of Blücher. De naam Rolandsspel is slechts te begrijpen, wanneer men aanneemt, dat er reeds ernstige Rolandsbeelden bestonden, en dat de pop, wegens zekere gelijkenis daarvan, spottenderwijs dien naam kreeg.

Maar nu onze Westfriesche Roland. Hij is volstrekt niet pas aan 't licht gekomen, doch voor zoover ik heb kunnen nagaan, heeft hij niet tot bijzondere opmerkingen aanleiding gegeven. Bij PoLS, Westfriesche Stadrechten ?) tweede deel, blz. 399, lezen wij onder de keuren, door schout en schepenen van Burghorn gemaakt, 'tot nutscappen van den gemeene lande van Borchorn' in 1505, als artikel 4 :

"Item so waer twee vrouwen kijven ende lelijcke hoeraefleche (lees: hoeraefteghe) woorden geven, die verbeuren elx $\mathrm{x} \mathrm{sc}$, off sy sullen twee uren aen Roelant staen op eenen rechtdach, ende dan malcander vergiffenisse bidden, off ten waer saeck dat den rechter docht, dat men se swaerlicke corrigeren soude".

Daar hebben wij dus den Roland, en wel zonder eenigen twijfel als kaak, in nauw verband met de rechtspraak derhalve. Een reeks van vragen knoopt zich aan deze plaats vast. In de allereerste plaats: is de lezing onbetwijfelbaar? De keuren van Burghorn zijn uitgegeven naar een Memoriaalboek behoorende tot het archief van den polder Burghorn, thans berustende onder den Provincialen archivaris van Noord-Holland te Haarlem. Dit Memoriaal bevat afschriften van de handvesten, keuren en andere stukken, deels naar de origineele charters, deels naar destijds nog bestaande oude registers of keurboeken, op 22 Februari 1622 door den notaris W. J. VAN Schoterbosch gecollationeerd en accoord bevonden. PoLs gebruikte echter voor de uitgave niet het Memoriaalboek zelf, maar een nauwkeurig afschrift, door Mr. G. DE VRIES Az. genomen. - Door de welwillendheid van den Heer GonNET, die het Memoriaalboek naar het Archief te Groningen zond, heb ik mij van de juistheid der lezing "aen Roelant" kunnen overtuigen (op blz. 25 van het Memoriaalboek). Die waarborg is voldoende, want het is ondenkbaar, dat een zoo zinrijke en onverwachte lezing door den afschrijver der oude keuren zou zijn verzonnen.

De tweede vraag, die zich voordoet, is: ontleende Burghorn deze keur en daarmede wellicht ook den Roland aan een andere Westfriesche stad? - De Westrriesche steden, zegt PoLs, ${ }^{2}$ ) schijnen na het bekomen van stadrecht dadelijk

1) Werken der Vereen. tot uitg. der bronnen van het Oude Vaderlandsche Recht, eerste reeks No. 7, I888, 2e deel 1885 .

2) t. a. p. II, bl. VII.

Oud-Holland i907. 
keurboeken te hebben aangelegd, grootendeels of geheel geput uit de keuren van een oudere stad. Hoorn, Enkhuizen, Grootebroek en Schellinkhout schijnen daarbij onmiddellijk uit de keuren van Medemblik te hebben geput, de andere steden ontleenen haar oudste keuren alle aan Schellinkhout. Die van Medemblik echter, in zekeren zin de grondvoorraad van Westfriesche stadskeuren, zijn niet bewaard. De keuren van Burghorn, de allerjongste Westfriesche stadstichting, zijn dan ook in hoofdzaak aan de naburige plaatsen ontleend, hoewel met meer wijziging dan gewoonlijk. Het artikel omtrent kijvende vrouwen wordt aangetroffen te Hoorn, Enkhuizen en Grootebroek. Het luidt aldaar:

Hoorn, Ond Keurboek, no. $25^{1}$ ): "Item waer twee wiven scelden, die verbueren elc tien scelling of den stien te draghen, ter goeder waerheit."

Nieuw Keurboek, no. $58^{2}$ ): "Item daer twie vrouwepersonen kyven, elcx sal verbueren thien stuvers of daervoer die stien draghen, tot discretie van schepenen."

Enkhuizen, no. 19 ${ }^{3}$ ): „Waer twie wyven sceelen (ander hs. scelden) die verboren elc tien scelling of den stien te draghen."

Grootebroek, no. I $2^{4}$ ): "Oeck so waer twie vrouwen kijven, die verbueren heerlick den stien te draghen of X scelling."

Een overeenkomst in de strafbepaling ${ }^{5}$ ) derhalve, die het waarschijnlijk maakt, dat het artikel reeds in de Medembliksche keuren voorkwam, maar nergens een spoor van den Roland. Ook elders mocht ik zulk een spoor niet ontdekken; de Roland van Burghorn blijft voorloopig een volkomen geïsoleerde verschijning.

Zoodoende rijst als derde vraag: Wat was dat Burghorn, dat zulk een Duitsch rechtssymbool moet hebben bezeten? - Het antwoord op die vraag doet het feit, dat juist hier de Roland opduikt, slechts te zonderlinger uitkomen: Burghorn is naar allen schijn nooit meer geweest dan een klein poldertje met een gehucht van ongeveer acht huizen en dertig inwoners.

Tusschen de Zijpe ten Noord-Westen en de Schagerwaard, die met de naburige meertjes de Noordelijke voortzetting vormde van de Heer Hugowaard, ten Zuid-Oosten verbond de smalle strook lands, waar Sint Maarten en Valkkoog liggen, Geestmerambacht met de Schager en Niedorper koggen. Een zeer belangrijk punt was het: de eenige toegangsweg te land van Kennemerland naar Westfriesland ${ }^{6}$ ), bij

1) t. a. p., bl. 24

2) ib., bl. 84 .

3) ib., bl. 196.

4) ib., bl. 240 .

5) Over de straf van het steenen dragen zie men Bijdragen voor Vad. Gesch., Nieuwe reeks, II bl. 21 ; vgl. Rechtsbronnen van Utrecht, I bl. 472; Friesche Stadrechten, 37, 96.

6) Behoudens de enkele dijk, die tusschen Alkmaar en Ursem de Waard van de Schermer scheidde, en bij Oterleek gemakkelijk door de West-Friezen kon worden afgesloten. 
den Zuidelijken hoek van de Zijpe door den Eenigenburg beschermd. Het was naar alle waarschijnlijkheid dit land, dat DiRK II aan het klooster te Egmond had geschonken. Nadat het geweld der zeevloeden er de dijken had verwoest en het land gedurende vele jaren vernield (annihilata) had gelegen, moet het kort vóor I250 door abt LUBBERT opnieuw met groote kosten zijn bedijkt ${ }^{1}$ ), en sedert draagt het den naam het Nieuweland van St. Maarten. Bij die nieuwe bedijking schijnt, naar de onderstelling van Mr. G. DE VRIES Az, door een inlaag, die den Westfrieschen zeedijk langs de Zijpe bencorden Valkkoog een kromming naar het Z.O. deed maken, een stuk land van omtrent 300 morgen tusschen St. Maarten en Schagen te zijn buitengedijkt en aan de Zijpe prijsgegeven, die daar voortaan dus een inham vormde.

Die inham is thans de polder Burghorn. Op 2 Maart 1456 verleende hertog Philips vaN Bourgondië aan Willem vaN SCHAGEN, bastaard van hertog ALBRECHT, op diens verzoek octrooi om te mogen bedijken "eenen ham off hoeck slijcklants buyten den voorsz. Vriesendijck binnen Gheestmanambochte dijckaedse, streckende al langes der heerlijkheyt van Schagen ende den ban van de Nieulandt, groit wesende omtrent driehondert mergen, als van sinte Martinskercke int voorsz. Nieulandt affgaende rechtuut tot Burchhorn." 2) Daarbij werd den Heer van Schagen de heerlijkheid over het nieuw te winnen land geschonken, ter vermeerdering van zijn heerlijkheid van Schagen. Volgens twee extracten, een uit een geschreven missaal in de parochiekerk te Schagen, een ander uit een dito te St. Maartenskerk werd met de bedijking in I 462 begonnen. ${ }^{3}$ ) Het schijnt, dat het werk Io Februari ${ }_{4} 463$ voltooid was; althans toen had de Schagerdam zijn functie van zeedijk reeds verloren, blijkens het privilegie, op dien datum door Heer WiLlem gegeven, omtrent een sluisje, door hem in den voormaligen zeedijk gelegd, waardoor de polder Burghorn voortaan in de Schagerkogge uitwaterde. ${ }^{4}$ )

De nieuwe polder kwam te liggen op de grens van het gebied, dat door de groote bestuursorganisatie van WILLEM VI in de jaren I408 tot $14 \mathrm{I} 5$ in zulk cen buitengewonen toestand was gebracht: de groepsgewijze vereeniging der Westfriesche dorpen onder stadrecht. Op de grens, want juist het Noordelijk

1) VAN DEN BERGH, Oorkb. v. Holl. en Zeel. I No. 533; G. DE VRIEs AzN., De Kaart van Hollands Noorderkwartier in 5288 , Verh. Kon, Akad. III, I865, bl. $23 \mathrm{vg}$.

2) Pols, t. a. p. I bl. Io6. Burghorn heette dus de noordhoek van den inham, wararschijnijjk naar den Eenigenburg.

3) Mem. van Burghorn, bl. 62; PoLs, t. a. p., I bl, III1.

4) Inventaris van het Archief van Schagen, Kronyk van het Historisch Genootschap XIII bl. 244. Vgl. G. DE VRIEs AzN., Het Dijks- en Molenbestuur in Holland's Noorderkwartier, Verh. Kon. Akad, X, I876, bl. 557 . 
deel van Geestmerambacht met Valkkoog en Sint Maarten was van die regeling uitgesloten gebleven. ${ }^{1}$ ) Wat Schagen betreft, waarmee Burghorn door zijn heer in nauwe relatie kwam te staan, op I2 Mei I4I5 was het door WILLEM VI als een der vier steden van Niedorperambacht met poortrecht begiftigd ${ }^{2}$ ), maar verbeurde dat met bijna alle Westfriesche steden wegens deelname aan den grooten opstand der Kennemers in 1426 door het vonnis van den hertog van Bourgondie van I 3 Augustus I 426. ${ }^{3}$ ) Een nieuwe politiek werd thans gevolgd: PHILIPS VAN BOURGONDIË vestigde in het Westfriesche gebied een aantal heerlijkheden, waarmee de aanvoerders, die zich verdienstelijk hadden gemaakt in het weerstaan van den opstand, en de bastaards van Beieren werden beschonken: WILLEM VAN BEIEREN, bastaard van Holland, admiraal van Holland en kastelein van Medemblik, kreeg in 1427 de heerlijkheid Schagen met die van Barsingerhorn, Haringhuizen, Colhorn en Keinze. Op 6 Augustus 1427 verleende de nieuwe heer opnieuw stadrecht aan Schagen, Barsingerhorn en Haringhuizen; ${ }^{4}$ ) de handvesten berusten evenals de vroegere op het stadrecht van Medemblik, dat is indirect op dat van Haarlem. Gaandeweg kregen ook de andere Westfriesche steden hun stadrecht opnieuw: Hoogwoude, dat als heerlijkheid aan EDUARD den bastaard was verleend, in $1450 .{ }^{5}$ )

Inmiddels had WILLEM VAN SCHAGEN de hem verleende heerlijkheid over het nieuw te bedijken gebied aan zijn jongeren zoon WILLEM gegeven, die er waarschijnlijk nog vóor den aanvang der bedijking, in 1462 , een handvest aan verleende, overgenomen van die van $H_{0 o g w o u d e}{ }^{6}$ ). Het eerste artikel luidt:

"In den eersten so sullen die van Burchorne wesen onder een poirtrecht, ende sal wesen een stede genoemt Burchhorn, ende sy sullen in den saken van der stede gebruyken een nieuwe zegel, dat sy doen sullen maken off sijs te doen hadden." - Uit "32 die rijcxste poorteren van der stede voorsz.", die drie jaar poorters waren geweest en ook te Burghorn hadden gewoond en schot en ongeld betaald, zou de heer jaarlijks op Nieuwjaarsdag vijf schepenen zetten. Maar er zijn waarschijnlijk nooit 32 poorters, laat staan rijke, in de stad Burghorn geweest. In 1477 wordt den heer van Burghorn vergund, om schepenen te kiezen uit twee of drie der naaste dorpen, omdat in Burghorn niet genoeg geschikte personen te

1) Pols, t. a. p. I, bl. XIX.

2) Pols, t. a. p. I, bl. XIX, $3^{6}$.

3) Handvesten van Haarlem, bl. 83. - Op i 2 April daaraanvonrafgaande had JACOBA aan die van Schagen op hun belofte van bijstand, vermeerdering van hun voorrechten beloofd; Kronyk v. h. Hist. Gen. XIII, bl. 243 .

4) Pols, t. a. p. I bl. XXVIII, 47; SChoorel, Chronyk van Schagen, bl. $5^{8}$.

5) ib. bl. 67 .

6) ib. bl. III. 
vinden zijn. $\left.{ }^{1}\right)$ Deze bepaling wordt ook opgenomen in de handvest, waarmee Jan van Schagen, die I4 Augustus I 475 de heerlijkheid verwierf, in 1489 de voorrechten van 1462 hetzij verving of uitbreidde: „Item ende om dies willen dat, onse vryheyt ende heerlickheit van Burchorn noch qualyken bewoont wesende, luttel ondersaten daer binnen geseten sijn, so sullen onse gesworen ende oock onse uutpoorters also wel scepenen ende in onsen gerechte mogen wesen, indien sy $\mathrm{bij}$ ons dairtoe gecoren worden als voorsz. is, als die binnen onse vryheyt ende heerlickheyt van Burchorn woonachtig ende geseten sijn". ${ }^{2}$ )

$\mathrm{E} r$ is geen aanwijzing, dat het ooit veel voorspoediger is geworden, al hebben schout en schepenen van Burghorn tot in het einde der i 8 e eeuw hunne functies vervuld. De Enqueste en de Informatie kennen den naam Burghorn in het geheel niet. In cen quohier van 1632 komt het voor met 9 huizen. ${ }^{3}$ )

Aan een deftig raadhuis, waarvoor een steenen Roland prijkt, zal hier dus wel niet te denken vallen. BURGHORN ontleende aan de handvest van Hoogwoude ook de bepaling "Waer men 't recht doen sal". "Item so sal men dat recht houden op vijff roeden na den kerckhove tot Burchhorn, des sullen die van Burchhorn aldair doen maken een huijs dair men die vierschaer in houden sal". ${ }^{4}$ ) - Of dat huis werkelijk is gebouwd? Een kerk schijnt Burghorn in het begin der I6de eeuw bezeten te hebben, hoewel daarvan noch bij VAN HEUSSEN, noch in de Taxatielijst der Proosdij van Westfrisia van I 509 iets wordt vermeld. ${ }^{5}$ ) Op 26 November 1507 maken JAN vaN Schagen en de schepenen met eenige poorters van Burghorn een dotatie ten behoeve van de cure en de pastorie van Burghorn, die toen van die van Schagen schijnt te zijn gescheiden, aangezien de schenkers tevens beloven, den pastoor van Schagen voortaan te zullen betalen "twie gouden hartoch Phlips gulden off paijment dier waerde voir d'offsnijdinge van de cure voorsz." ") De kerk stond er blijkbaar reeds, want terwijl het stuk de belofte bevat, "te doen maken tot onsen costen een eerlyck Priesterhuys tot behoeff des cures (sic) ende pastoirs voorsz.", wordt van de kerk gesproken in dezer voege :onder de landerijen, die JAN vaN SCHAGEN schenkt is "een gars lants in die vier ackeren omtrent die noortsijdt van de selve kercke van Burchorn gelegen". ${ }^{7}$ ) Een kerk, die nog gebouwd moet worden, gebruikt men toch niet, om een belending aan te wijzen. Ook de keuren van 1505 spreken in verschillende artikelen van een blijkbaar bestaande kerk.

1) Archief van de Heeren en de Heerlijkheid van Schagen, Verslagen omtrent 's Rijks oude Archieven XXV bl. I79, 207; ook reeds vermeld Kronyk v. h. Hist. Gen., IX, bl. 41.

2) POLs, t. a. p. I b. II6.

3) Dirk Burger van Schoorel, Chronyk van de stad Medemblik, i736, b1. I $8 \mathrm{r}$.

4) Mem. van Burghorn, bl. I2.

5) Bronnen voor de Geschiedenis der Kerkelijke Rechtspraak in het bisdom Utrecht in de Middeleeuwen, uitg. door Mr. J. G. C. Joosting en Mr. S. Muller IIzN., I bl. 393 (O. V. Rb. 2e reeks VIII.)

6) Mem. van Burghorn, bl. 87. 7) ib. 
Het blijft wat vreemd: de kerk heeft, naar 't schijnt, niemand later weergezien, en of ooit het priesterhuis, waarvan de dotatie spreekt, en het rechthuis, dat de handvest van $I_{4} 62$ voorspelt, werkelijk zijn verrezen? ik acht het hoogst onwaarschijnlijk.

De gegevens, die men voor de vraag: wat was de gedaante en de plaats van dien Roland, uit de plaatselijke gesteldheid van Burghorn afleiden kan, zijn van louter negatieven aard. Zelfs zou ik niet al te stellig durven beweren, dat het inderdaad een menschelijke figuur is geweest, en niet eenvoudig een kaak of schandpaal van het gewone model. Tweemaal toch wordt in de handvest van Burghorn van 1489 de kaak genoemd, zonder dat er van Roelant sprake is: art. $4 \mathrm{r}:, \ldots$ so wie eenen quaden eedt sweert ende daeroff betuycht wort mit twee tuygen, die sal ons gelden $\mathrm{X}$ pont, off hy sal drie dagen aen een ecn uur lanck op die kake staen enz." 1 ); art. $6_{3}:, \ldots$ men sal denselven eer-, seker- ende trouwelose persoon by onsen scout ende gerechte corrigeren, op een kaek te stellen ende anders, nae gelegentheyt van de saicke ende na den beschreven rechte." $)$

Misschien vindt men daaromtrent nog een zijdelingsche opheidering in het volgende feit. In sommige Westfriesche steden wordt de kaak aangeduid met de benaming de Potboef. De Chronyk van ae vermaarde Zee en Koopstad Hoorn van FEIKEN RiJP (I706) vertelt ${ }^{3}$ ), hoe te Hoorn in 1673 een opstootje plaats had van ruiters daar in garnizoen tegen matrozen. Als belhamel zou een der ruiters voorbeeldig worden gestraft. „Dese knaap dan wierd gevonnist, om een sekere tijd aan de schandpaal te pronk te staan, welke schandpaal geplaast was digt bij het stadhuys, aan de sijde van de kaak, of so genaamde Pot-boeff." En DIRK BURGer vaN SChOOREL verhaalt in zijn Chronyk van Medenblik ${ }^{4}$ ) op het jaar I7IO: „Den 2 October hebben die van Twisk, Opperdoes en Medenblik, een partij van 30 a 40 stuks Heydens, zoo oude als jonge, tot Abbekerk gebragt, dewelke daar in 't gat wierde gezet, ende den volgende dag zijnde den 3 October, wierden 'er 4 a 5 aan de Potboef gezet, en met modder gegooyt, en doen altemaal uytgebannen, behalven een Mans Perzoon, dewelke sat tot den 6 October, en wierd doen meede aan de Potboef gezet, en met modder gegooyt, en voor 25 jaar gebannen". ${ }^{5}$ )

1) Pols, t. a. p. I bl, I26. $\quad$ 2) ib. bl. I32.

3) bl. 237. De soldaat verkoos den dood boven de schandpaal, en werd gefusilleerd.

4) bl 347 .

5) De stad Abbekerk was in I4I4 gevormd uit de dorpen Abbekerk, Twisk, Midwoude en een dee van Lambertskage. De handvest van $\mathrm{I}_{4} \mathrm{I}_{4}$ verm: ldt: "Ende dat recht sal men besitten in den prochien van Abbenkerck op vijf ende twintich roede na den kerchove" (PoLs, I bl. 33.) Daar stond in de I8e eeuw 't gemeene Raadhuis, waar men dus de kaak te zoeken heeft. (Tegenw. Staat van Holland, V bl. 459.) - Eij hun heidenjacht handelden de burgers naar een keur van I53I: ,waer 't zaacke dat er eenige overlast van bocven ende rabouwen ofte anders quam, ende die clocke geklept worde, dat alle man elk in zijn dorp malkanderen bijstaan moeten, aldaar zij het geruchte hooren, op ecn boete van III pont." (PoLs, II bl. $3^{8} 3$ ). 
De Potboef. 't Is wel heel wat anders dan Karel's paladijn. KiliaAN zegt: "potboeve-Nebulo vagus et validus, encaenia et festa genialia passim consectans: a liguriendis ollis sive poculis dictus." l) Moet het ons wellicht in verband met den Roland van Burghorn aan een kaak in de gedaante van een menschelijke figuur, in West-Friesland gebruikelijk, doen denken? Wie lust heeft, mag ja zeggen, en zich zelfs voorstellen, dat die potboeven van Hoorn en Abbekerk eertijds ook Roelant hebben geheeten. Voorzichtiger schijnt het mij, zich van zulke gissingen te onthouden.

Waar al de vorige vragen ons reeds tot zulke povere uitkomsten leidden, daar blijft de belangrijkste vraag: hoe is Burghorn aan zijn Roland gekomen? natuurlijk geheel zonder bevredigend antwoord. Een toevallige importatie uit Duitschland schijnt mij het aannemelijkst. Maar hoe? De Wittelsbachsche herkomst der SCHAGEN's kan het ons niet verklaren. Hun vrouwen zijn in de $15^{\mathrm{e}}$ eeuw alle uit den Hollandschen adel: Hodenpyl, Bokkhorst, Swieten, enz. ${ }^{2}$ ) - Was het Hoorn of Enkhuizen, waar wij den Roland aantroffen, dan lag de veronderstelling voor de hand, dat een of ander varensgast van Duitsche reizen den naam, misschien ook de zaak, had ingevoerd. Had de brave schoolmeester VALCOOCH ons in zijn wonderlijke Chronyk van de Zijpe maar wat van zijn fantazie gespaard voor een korte opheldering!

Zoo zou ik tenslotte als positieve uitkomst van dit onderzoek geen ander weten te noemen dan dat HeLdmann's bewering, dat de benaming, "Rolanden" voor schandpalen of kaken eerst aan de geleerde litteratuur der laatst verloopen eeuwen te danken is ${ }^{3}$ ), er ten stelligste door wordt ontzenuwd, en RiETSCHEL's e rklaring er zoodoende een indirecten steun door verwerft. ${ }^{4}$ )

Voor de volledigheid dient hier ook nog even de Roland van Amsterdam besproken te worden. In tegenstelling met dien van Burghorn, ons enkel bij name overgeleverd, bezitten wij van hem beschrijvingen en afbeeldingen. Toch kan hij mijns inziens veel minder op authenticiteit aanspraak maken. ${ }^{\mathfrak{5}}$ )

Onze berichtgevers zijn: WaGenaAR in zijn Amsterdam ${ }^{6}$ ), LE FrancQ

1) Etymologicum, i. v., met een paar bewijsplaatsen in de noot. Vgl. Mnl. Woordenboek i.v. Potridder.

2) VAN LEEUWEN, Batavia illustrata, 1078.

3) Die Rolandsbilder Deutschlands, S. 22.

4) Hierbij zij nog gewezen op hetgeen VAN OOSTEN DE BRUYN omtrent het opgerichte zwaard in het Haarlemsche wapen opmerkt: ,Zoo geloof $\mathrm{ik}$, dat 't zwaard in ons stads wapenschild, van d'oudste Hollandse Graaven afkomstig, en daarin gesteld is ten teken van 't Hooge Graaflijke Rechts-gebied, 't welk binnen deeze Stad, in oude tijden, allermeest, immers over geheel Kennemerland geoefend is." De stad Haarlem en haare Geschiedenissen, I765, bl. 47. Hij zegt verder, dat Schrevelius, Harlemum p. 8 dit ook als gevoelen van Boxhors aanhaalt.

5) Het Beiblatt zur Magdeburger Zeitung, 1890, No. 9-19, waar SELlo ook den Amsterdamschen ROLAND moet hebben besproken, was mij niet toegankelijk.

6) Jan WagenaAr, Amsterdam in zijne opkomst, aanwas, geschiedenissen enz., Tweede stuk, 1765, bl. 414 . 
Berkhey in zijn Natuurlijke Historie van Holland ${ }^{1}$ ) en de Naamlooziana. ${ }^{2}$ ) Het laatste geschriftje geeft een afbeelding (door C. PHILIPS JACoBsz, I772) ook BERKHEY, maar deze heel klein en schetsachtig. Wij vernemen dan, dat er in de I 8 e eeuw een oud beeld, in de wandeling Steenen Roeland genaamd, stond aan de Nieuwe Zijds Voorburgwal tegenover de Kolk, in de stoep van het vierde huis van de Pottebakkerssteeg. Een zeer fraaie teekening van het huis, waarop te zien is, hoe de Steenen Roeland er vóór stond, werd door den Heer MOES teruggevonden in den Atlas van den Heer R. W. P. DE VRIES. Zij is van GERRIT LAMBERTS, die er achterop schreef: "de Steene Roeland gestaan hebbende voor een huis op de N. Z. Voorburgwal over de Kolk, weggebroken in $a^{\circ}$. I774. G. LAMBERTS I8I6 na eene oude afbeelding." Het huis draagt het jaartal r62 I in den gevel. Volgens WAGENAAR heet het huis reeds in de oudste opdrachtbrieven (hoe oud, vermeldt hij niet) van ouds Steenen Roeland. Het beeld was in kleuren beschilderd, maar zeer gehavend, erger dan de atbeelding van PHILIPS weergeeft, zooals het Vertoog in de Naamlooziana zelf zegt. De voeten stonden in den grond, zegt BERKHEY, wiens afbeelding dat ook aangeeft; de handen ontbraken. De geheele lengte, de voeten erbij geraamd, bedroeg omtrent zes voet.

De afbeeldingen laten mij dunkt door de kleederdracht weinig twijfel, of wij hebben te doen met een beeld uit de eerste helft der $16^{\mathrm{e}}$ eeuw: men zie slechts de baret, de geplooide rok, de hozen. In de breede schouderbedekking zien WAGENAAR en BERKHEY een pantser, de Naamlooziana een wammes met korte wijde mouwen, zooals de Markers dragen (wat mij waarschijnlijker lijkt).

Het merkwaardigste is wel, dat het beeld volgens WAGENAAR en BFRKHEY, "zo 't schijnt, eertijds een opgeheeven zwaard in de hand gehad" heeft, en dat het voor de borst een schild, waarop een staand kruis van eigenaardigen vorm draagt, gelijk de afbeelding in de Naamlooziana duidelijk doet zien.

Twee jaar nadat PHILIPS hem afbeeldde, is Steenen Roeland verdwenen: op 4 Januari 1774 werd hij, „zeer beschadigd zijnde, door tijd en ouderdom” op last van burgemeesteren door stadswerklieden weggenomen ${ }^{3}$ ).

Hoe hebben wij dezen Amsterdamschen Roland op te vatten? WAGENAAR kent reeds de geleerde verklaring, die in de Duitsche Rolandsbeelden de teekenen van een vrije markt ziet, en past die ook op dezen toe. ${ }^{4}$ ) Men placht, zegt hij,

1) J. Le France van Berkiey, Natuurlijke Historie van Holland, Derde deel, eerste stuk, 1776 bl. $488 \mathrm{vg}$.

2) De Naamlooziana of Vertoog zonder naam over vraagen zonder vinding, te Amsteldam bij C. PHILIPS j. z. 1772, bl. $309-320$.

3) Amsterdam in zijne geschiedenissen, ten vervolge op JAN WAGENAAR, I788, op I774.

4) Hij citeert daarvoor de noten bij Struvir, Corp. Hist. Germ. per. IV. Sect. I p. I 24, en bij EginhaRd's, Vita Caroli, cap. 9, p. 55, edit. Schminkii. 
van de bijzondere vorstelijke bescherming voor de markten kennis te geven door het oprichten van marktkruisen, in Duitschland van houten of steenen gewapende beelden, Roelands beelden genaaind; ook dien van den Nieuwe Zijds Voorburgwal acht hij tot dat doel opgericht. Ter bevestiging tracht hij te bewijzen, dat aldaar eertijds werkelijk markt is gehouden. De Naamlooziana volgt hem daarin en betoogt verder, dat het stadhuis eenmaal op de Kolk zou hebben gestaan. BERKHEY, hoewel hij WAGENAAR aanhaalt, acht het beeld in de achtste eeuw ter gedachtenis aan Roland opgericht!

Dat de Amsterdamsche Roland inderdaad eenmaal het officieel karakter van zijn Duitsche verwanten zou hebben bezeten, 't zij dan markt- of gerechtssymbool, schijnt mij zeer onaannemelijk. WAGENAAR's betoog, dat de plaats, waar hij stond, eertijds marktplaats zou zijn geweest, wordt door TER Gouw verworpen ${ }^{1}$ ). Indien werkelijk, zooals oude Amsterdammers beweerden, vroeger nog twee andere Roelant's op andere plaatsen binnen Amsterdam hebben gestaan ${ }^{2}$ ), wordt de kans nog geringer, dat het iets anders zijn geweest dan huisbeelden, sieraden. Het waarschijnlijkst is dan wel, dat een of ander scheepskapitein den paladijn, dien hij op Duitsche reizen had leeren kennen, in de stoep van zijn huis een eereteeken heeft willen stichten. Het schild op de borst wijst de herkomst nog duidelijker aan: de Bremer Roland of een zijner volgelingen moet hier tot voorbeeld hebben gestrekt. ${ }^{3}$ )

De bijkans paganistische vereering, die de Bremers aan hun stedelijk palladium wijdden, heeft onze Amsterdamsche vriend dan ook stellig nimmer genoten; wel een gemeenzame populariteit. In spreekwijzen was hij doorgedrongen: "stiene Roeland" noemde men een stijve Klaas of iemand, die van schrik versteef ${ }^{4}$ ); van een waardelooze vordering heette het: „men zal hem een briefje afgeven op steenen Roeland" "), en wie kwalijk uitgeslapen van een nachtelijken roes verscheen, kon hooren : ,je hebt te nacht met den steenen Roeland gevochten." 6 )

1) Ter Gouw, Amsterdam V, bl. 64; Oude Tijd, 1872, bl. 355 vg.; Uithangteekens I, bl. $33^{8}$.

2) KoK, Amsterdamsche Jaarboeken, III bl. $45 \mathrm{I}$.

3) TER Gouw kent te Coevorden een uithangbord van een herberg: "In Roeland van Brecmen", Uithangteekens, I bl. 338 .

4) Asselijn, 't Kraambedt enz.; WolfF en Deiren, Willem Leevend, Oude Tijd I872, 355, HarreBOMEe, Spreekwooldenboek II bl. 224 .

5) HARREBOMEe, t. a. p.

6) Ter Gouw, Uithangteekens, I bl. $33^{8}$; Vgl. Naamlooziana, bl. 309 .

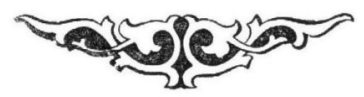

